\title{
BMJ Open Observing temporal trends in cardiac rehabilitation from 1996 to 2010 in Ontario: characteristics of referred patients, programme participation and mortality rates
}

\author{
Sherry L Grace, ${ }^{1,2}$ Paul I Oh, ${ }^{2,3}$ Susan Marzolini, ${ }^{2}$ Tracey Colella, ${ }^{2,3}$ Yongyao Tan, ${ }^{2}$ \\ David A Alter ${ }^{2,3}$
}

To cite: Grace SL, Oh PI, Marzolini S, et al. Observing temporal trends in cardiac rehabilitation from 1996 to 2010 in Ontario: characteristics of referred patients, programme participation and mortality rates. BMJ Open 2015;5: e009523. doi:10.1136/ bmjopen-2015-009523

- Prepublication history for this paper is available online. To view these files please visit the journal online (http://dx.doi.org/10.1136/ bmjopen-2015-009523).

Received 24 July 2015 Revised 22 September 2015 Accepted 14 October 2015

CrossMark

${ }^{1}$ School of Kinesiology and Health Science, York University, Toronto, Ontario, Canada

${ }^{2}$ Cardiac Rehabilitation and Prevention Program, Toronto Rehabilitation Institution, University Health Network, Toronto, Ontario, Canada ${ }^{3}$ Department of Medicine, University of Toronto,

Toronto, Ontario, Canada

Correspondence to Dr Sherry L Grace; sgrace@yorku.ca

\section{ABSTRACT}

Objectives: We sought to describe temporal trends in the sociodemographic and clinical characteristics of participants referred to cardiac rehabilitation (CR), and its effect on programme participation and all-cause mortality over 14 years.

Setting: A large CR centre in Toronto, Canada.

Participants: Consecutive patients between 1996 and 2010.

Primary and secondary outcome measures: Referrals received were deterministically linked to administrative data, to complement referral form abstraction. Out-of-hospital deaths were identified using vital statistics. Patients were tracked until 2012, and mortality was ascertained. Percentage attendance at prescribed sessions was also assessed.

Results: There were 29171 referrals received, of which $28767(98.6 \%)$ were successfully linked, of whom $22795(79.2 \%)$ attended an intake assessment. The age of the referred population steadily increased, with more females, less affluent and more single patients referred over time $(p<0.001)$. More patients were referred following percutaneous coronary intervention and less following coronary artery bypass graft surgery $(p<0.001)$. The number of comorbidities decreased $(p<0.001)$. Hypertension increased over time $(p<0.001)$, yet the control of cholesterol steadily improved over time. The proportion of smokers decreased over time $(p<0.001)$. Participation in CR significantly declined, and there were no significant changes in mortality. 3-year mortality rates were less than $5 \%$.

Conclusions: Characteristics of referred patients tended to reflect broader trends in risk factors and cardiovascular disease burden. Physicians appear to be referring more sociodemographically diverse patients to CR; however, programmes may need to better adapt to engage these patients to fully participate. More complex patients should be referred, using explicit criteria-based referral processes.

\section{INTRODUCTION}

Similar to many other Western nations, temporal trends of decreasing incidence of
Strengths and limitations of this study

- This is the first study to describe temporal trends in cardiac rehabilitation referrals received from inpatient and outpatient settings.

- The cohort is very large, and mortality is ascertained through linkage to administrative data.

- However, the design was observational, and therefore some alternative explanations for the associations observed cannot be ruled out.

- Also, this was a single-centre study, and hence generalisability to other centres is unknown.

cardiovascular disease (CVD) have been observed in Ontario, Canada. ${ }^{1}$ Fewer acute coronary syndromes, decreasing mortality and a shift towards more percutaneous coronary intervention relative to bypass surgery is also observed. This trend of decreasing CV burden has emerged despite a demographic shift towards an older population, with greater prevalence of $\mathrm{CV}$ risk factors such as obesity and diabetes. ${ }^{2}$ This inconsistency can partially be attributed to advances in acute therapies for CVD, such that more patients are surviving episodes of acute coronary syndrome. Subsequently, there are many patients discharged from hospital requiring secondary prevention to mitigate the high risk of a recurrent episode.

Cardiac rehabilitation (CR) is an outpatient chronic disease management programme, supporting provision of secondary prevention and lifestyle changes, which successfully reduces the risk of recurrence and mortality. ${ }^{3}$ Accordingly, clinical practice guidelines recommend $\mathrm{CR}$ referral for patients with CVD. ${ }^{4}$ Unfortunately, however, there is insufficient capacity to treat all indicated patients. ${ }^{5}$ In Ontario specifically, for 
example, it has been established that there is only enough CR capacity to provide services to $34 \%$ of the eligible population. ${ }^{6}$ Emphatic calls to promote greater CR access have been sounded by learned societies. ${ }^{78}$ Systematic referral of patients ${ }^{9}$ has been shown to increase utilisation, ${ }^{10}{ }^{11}$ and some studies have suggested this has the ancillary advantage of ensuring all patients, regardless of their sociodemographic characteristics, have greater access to $\mathrm{CR}^{12}$ Known resource capacity constraints may however influence which cardiac patients' physicians chose to refer.

While recent research has considered trends in the characteristics of referred inpatients, ${ }^{13}{ }^{14}$ there has not been corroborating data from CR programmes examining the nature of referrals received, to establish whether population-level trends are reflected among the patients referred. Moreover, a changing patient demographic would likely have an impact on enrolment and programme adherence rates, and subsequently mortality, although the latter has not been previously investigated to our knowledge. For instance, it has been observed that women and patients of lower socioeconomic status, for example, are less likely to enrol and adhere to CR. ${ }^{15}{ }^{16}$ In consequence, given the dose-response association between CR participation and mortality, ${ }^{17}$ these patients may subsequently die at a higher rate.

Accordingly, the objectives of this study were to describe: (1) trends in the sociodemographic and clinical characteristics of patients referred to CR, (2) rates of programme participation, and (3) all-cause mortality, over time. It was hypothesised that the characteristics of referred patients would reflect the temporal trends observed in the population of patients with CVD more broadly, and that these patients may be less adherent to CR.

\section{METHODS}

The following was an observational cohort study.

\section{Setting}

This study was conducted at the University Health Network Cardiovascular Prevention and Rehabilitation Program, Toronto Rehabilitation Institute, Ontario, which provides comprehensive $\mathrm{CR}$ in accordance with Canadian CR Guidelines. ${ }^{18}$ The programme is situated proximate to a hospital offering advanced cardiac services. The health region in which the programme is situated has an annual volume of 3863 cardiac hospitalisations, and CR capacity to treat $86.7 \%$ of this population. $^{6}$

Referrals are made at the discretion of patients' physicians. Accepted indications for the programme are chronic coronary artery disease, acute coronary syndrome, percutaneous coronary intervention, coronary artery bypass graft surgery, valvular disorders, arrhythmias and heart failure. There is also a primary prevention stream for patients with multiple risk factors for
CVD, including a diabetes-specific stream which was initiated in 2004.

There is no charge to attend the programme, although there are parking fees. The intake assessment includes determination of marital status, comorbidities and cardiovascular risk factors. The latter includes diabetes, hypertension, smoking status, lipid profile and anthropometrics. A graded exercise stress test was also performed on a treadmill or cycle ergometer with measurement of peak oxygen uptake.

The programme model has been described previously. ${ }^{19}$ At the time of the study, the programme comprised two phases: the active phase consisted of between 24 and 36 prescheduled weekly supervised exercise sessions, while the maintenance phase consisted of monthly on-site visits and continued home-based exercise sessions recommended five times per week. The reduction in prescheduled sessions from 36 to 24 was undertaken to increase programme capacity.

\section{Data sources}

This sample consisted of all consecutive patient referrals received between 1 January 1996 and 31 December 2010, which were tracked until 31 March 2012. There were no exclusions. All patients were deterministically linked to administrative data to complement referral form abstraction. An encrypted health card number allows a patient to be tracked longitudinally through health service encounters, hospitalisations and death.

Canadian Institute for Health Information maintains the Discharge Abstract Database (DAD) which captures administrative, clinical and demographic information on all hospital discharges (including deaths) in Ontario. The aetiology of the most proximal hospitalisation was extracted based on the 'most responsible diagnosis' of said hospitalisation. Patient comorbidities were identified using the diagnostic fields from the DAD within the 5 years preceding CR referral. Out-of-hospital deaths were also identified using vital statistics.

\section{Measures}

Most sociodemographic and clinical characteristics of referred patients were ascertained from completed referral forms and administrative databases, as outlined above. Socioeconomic status quintile was computed by cross-referencing patient postal codes with the average household income in the province of Ontario by area from census data, with one being the lowest. Referral indication as reported on the referral form by the physician was coded in prioritised fashion, so each patient's primary indication was mutually exclusive, with acute coronary syndrome given first priority. Laboratory test results, anthropometrics, functional capacity, as well as smoking and marital status were available only on the patients who attended the CR intake assessment.

CR participation was defined in terms of: (1) whether the patient attended an intake assessment, and if yes (2) as the percentage of prescribed weekly on-site sessions 
attended among those who initiated the programme postintake. The outcome for the third objective of this study was all-cause mortality within 1, 2 or 3 years following the expected completion date of CR (ie, end of prescheduled visits as per programme model including maintenance phase), regardless of whether or not the patient actually enrolled or fully participated in the programme.

\section{Statistical analyses}

The sociodemographic and clinical characteristics of patients referred from 1996 to 2010 was collected for each year. Each baseline characteristic was reported as a mean (with SD of the means) or proportion as appropriate for each year of follow-up. Statistical tests for temporal differences in baseline referral characteristics, programme participation and mortality employed the Mantel-Haenszel $\chi^{2}$ test with one-degree of freedom for categorical variables, and least-squares regression for continuous variables examining differences in group means over time. Statistical significance was defined as a two-sided $\alpha$ of 0.05 . All analyses were conducted using SAS V.9.3 (Cary, North Carolina, USA) in 2014.

\section{RESULTS}

There were 29171 consecutive unique patients referred, of which 28767 (98.6\%) were successfully linked to administrative data. Age, sex, socioeconomic status, comorbidity and mortality data were available on all patients through linkage. However, the availability of other clinical data varied, ranging from as low as $28.7 \%$ (8263/28 767) for serum lipids to $79.2 \%$ (22 795/ 28 767) for body mass index; cardiopulmonary fitness data were available for $75.9 \%$ (21 842/28 767) patients, while data on programme participation/on-site attendance were available for $70.2 \%$ (20 198/28 767). The average duration for mortality follow-up was 8 years.

The number of patients referred per year is shown in table 1 . The number was consistent over the first 10 years, and increased in the 5 most recent years.

\section{Temporal trends in characteristics of referred patients}

The sociodemographic and clinical characteristics by time period are also shown in table 1 , and some key parameters are exhibited in figure 1. As displayed, there were significant trends for all characteristics except peak oxygen uptake from the intake stress test. The age of the referred population appeared to be steadily increasing (especially for those $>80$ years), as well as the proportion of females. More patients who were less affluent and single were observed to be referred over time.

Referral indications for all-comers (ie, those referred as inpatients or outpatients) as per referral forms appeared to reflect change in overall cardiac interventional practices towards more percutaneous coronary intervention for acute coronary syndrome and less coronary artery bypass graft surgery (table 1). Increased referral of patients with 'other' indications, such as heart failure, arrhythmias, valve disorders and cardiomyopathy, was also observed. When considering aetiology of the most recent hospitalisation for the referred inpatients, however, very few and a decreasing proportion of patients were referred following percutaneous coronary intervention, but similarly there was a decreasing proportion of patients referred for bypass surgery. Referral of inpatients for heart failure was low and remained low throughout the period of study. The proportion of outpatients referred doubled to one-fifth over the 14-year span.

With regard to risk factor burden (table 1), the prevalence of diabetes increased over time; however, this is likely a reflection of greater provision of comprehensive rehabilitation for this high-risk population. Hypertension increased over time, yet the control of cholesterol seemed to be steadily improving over time. The proportion of smokers decreased over time. Body composition appeared consistent for the first 10 years, but appears to have increased substantively in the past 5 years. Finally, the number of non-cardiac comorbidities present among the referred population seemed to be decreasing over time, with a slight increase in cardiac comorbidities (table 2).

A sensitivity analysis was undertaken, where patients referred specifically for diabetes only and/or primary prevention was excluded. No meaningful differences in results emerged.

\section{Participation and mortality}

The CR participation and death rates are shown in table 3 and figure 1. In total, $5590(19.4 \%)$ patients were referred, but never attended any visits (ie, non-attenders), and 3831 $(13.3 \%)$ attended an intake assessment only. The median and mean percentages of CR sessions attended across all years were $63.9 \%$ and $58.4 \%$, respectively. As shown, about a quarter of referred patients did not initiate the CR programme.

As also shown in table 3 and figure 1 , adherence to the programme declined over time. A second sensitivity analysis in which attendance was restricted to only the first 12 weeks of eligible visits did not meaningfully alter these findings, such that on-site attendance to eligible visits still dropped steadily over time.

There were no significant changes in mortality temporally (table 3 and figure 1). Overall, mortality rates were low.

\section{DISCUSSION}

While some recent studies have reported on CR referral rates and characteristics of referred patients, previous data have primarily stemmed from inpatient settings, ${ }^{13}$ or only included enrolled patients. ${ }^{20}$ This study has been the first to demonstrate temporal trends in referrals received from inpatient and outpatient settings. When considering patients' sociodemographic characteristics, a 


\begin{tabular}{|c|c|c|c|c|c|c|c|c|c|c|c|c|c|c|c|c|}
\hline jeline charact & $\begin{array}{l}\text { Year } \\
1996\end{array}$ & 1997 & 1998 & 1999 & 2000 & 2001 & 2002 & 2003 & 2004 & 2005 & 2006 & 2007 & 2008 & 2009 & 2010 & \\
\hline $\mathbf{v}$ & 1545 & 1773 & 1818 & 1736 & 1586 & 1596 & 1686 & 1444 & 1799 & 2041 & 2532 & 2374 & 2188 & 2298 & 2351 & \\
\hline \multicolumn{17}{|l|}{ iodemograph } \\
\hline Age (mean years $\pm S D$ ) & $59.8 \pm 0.28$ & $.0 \pm 0.26$ & $.1 \pm 0.25$ & $9.6 \pm 0.28$ & $0.9 \pm 0.28$ & $60.8 \pm 0.28$ & $61.2 \pm 0.27$ & $61.4 \pm 0.30$ & $61.5 \pm 0.27$ & $61.2 \pm 0.26$ & $61.0 \pm 0.24$ & $61.6 \pm 0.25$ & $61.6 \pm 0.26$ & $62.0 \pm 0.26$ & $62.1 \pm 0.26$ & $<0 . c$ \\
\hline$<50, n(\%)$ & $294(19.0)$ & $294(16.6)$ & $306(16.8)$ & 331 (19.1) & $243(15.3)$ & $249(15.6)$ & $245(14.5)$ & $227(15.7)$ & $280(15.6)$ & 354 (17.3) & 439 (17.3) & $398(16.8)$ & 355 (16.2) & 373 (16.2) & 359 (15.3) & $<0.001$ \\
\hline $50-64, n(\%)$ & $691(44.7)$ & $821(46.3)$ & $36(46.0)$ & 80 (44.9) & 708 (44.6) & $729(45.7)$ & $754(44.7)$ & $608(42.1)$ & $786(43.7)$ & $862(42.2)$ & $1085(42.9)$ & $993(41.8)$ & 924 (42.2) & 932 (40.6) & $1003(42.7)$ & \\
\hline $65-79, \mathrm{n}(\%)$ & 537 (34.8) & 624 (35.2) & $643(35.4)$ & $585(33.7)$ & $584(36.8)$ & $570(35.7)$ & $614(36.4)$ & $531(36.8)$ & $629(35.0)$ & 715 (35.0) & 859 (33.9) & $822(34.6)$ & 771 (35.2) & $823(35.8)$ & $803(34.2)$ & \\
\hline $80+, n(\%)$ & $23(1.5)$ & $34(1.9)$ & $33(1.8)$ & $40(2.3)$ & $51(3.2)$ & $48(3.0)$ & $73(4.3)$ & $78(5.4)$ & $104(5.8)$ & $110(5.4)$ & $149(5.9)$ & $161(6.8)$ & $138(6.3)$ & $170(7.4)$ & $170(7.9)$ & \\
\hline \multicolumn{17}{|l|}{ Sex } \\
\hline Male, $n$ & $1186(76.8)$ & $1370(77.3)$ & $19(78.1)$ & $1363(78.5)$ & $1206(78.6)$ & $1206(75.6)$ & $1282(76.0)$ & $1102(76.3)$ & $1286(71.5)$ & $1340(65.7)$ & $1643(64.9)$ & $1571(66.2)$ & $1506(68.8)$ & $1567(68.2)$ & $1603(68.2)$ & $<0.0$ \\
\hline Female, $\mathrm{n}(\%)$ & $359(23.2)$ & $403(22.7)$ & $399(22.0)$ & $373(21.5)$ & $339(21.4)$ & $390(24.4)$ & $404(24.0)$ & 342 (23.7) & $513(28.5)$ & 701 (34.4) & $889(35.1)$ & $803(33.8)$ & $682(31.2)$ & 731 (31.8) & $748(31.8)$ & \\
\hline \multicolumn{17}{|l|}{ Marital statust } \\
\hline \multirow{2}{*}{\multicolumn{17}{|c|}{ Neighbourhood income quintile }} \\
\hline & & & & & & & & & & & & & & & & \\
\hline Quintile 1, n (\%) & 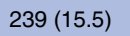 & 7) & .9) & .1) & $223(14.1)$ & $242(15.8)$ & $265(16.1)$ & 0) & 1) & 1) & 0) & 3) & $87(22.4)$ & 9.3) & 9.3) & 0.0 \\
\hline Quintile 2 & $267(17.3)$ & $312(17.6)$ & $291(16.0)$ & $21(18.5)$ & $245(15.5)$ & $248(15.6)$ & $254(18.4)$ & 265 (16.5) & $295(17.6)$ & 357 (17.6) & 520 (20.6) & 458 (19.4) & 389 (17.9) & 450 (17.8) & 417 (17.8) & \\
\hline Quinti & $293 i$ & 9) & 9) & 9) & 5) & 7.0) & $6.0)$ & 5.4) & & & & 15.3) & 318 (14.6) & 355 (14.6) & 342 (14.6) & \\
\hline Quintil & 8) & $335(1$ & $22(1$ & 6 (17.7) & 09 (19.5) & $317 i$ & 333 (17.9) & (17.6) & $6.6)$ & $6.6)$ & $6.9)$ & 407 (17.2) & $93(18.1)$ & 370 (17.6) & $413(17.6)$ & \\
\hline Quintile 5, n (\%) & & $545(3$ & 38 & & & & & & & & & 26.9) & $89(27.1)$ & $673(29.4)$ & 719 (30.7) & \\
\hline \multicolumn{17}{|l|}{ Referral indicationt } \\
\hline ACS, $n(\%)$ & .4) & .8) & .0) & 8) & 0) & C) & (2) & (1) & & & & & 1) & & 4) & $20.6+2>$ \\
\hline CABG, & .3) & $638(36.0)$ & $624(34.3)$ & $.0)$ & 561 & 540 & .4) & $.5)$ & 5.7) & & $3.0)$ & 7.8) & 9.2) & 17.0) & 401 (17.1) & \\
\hline Chronic & $3(7.3)$ & $80(4.5)$ & $105(5$ & (4. & $97(6$ & $85(5) \div$ & 10 & 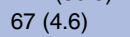 & & & & & 0.2) & 261 (11.4) & 289 (12.3) & \\
\hline $\mathrm{PCl}, \mathrm{n}($ & (7.4) & $178(10.0)$ & $186(10.2)$ & $194(11.2)$ & $167(10.5)$ & $369(23.1)$ & $2.1)$ & $0.4)$ & & & & 2.2) & $56(25.4)$ & $599(26.1)$ & 617 (26.2) & \\
\hline $\begin{array}{l}\text { Diabetes and/or primary } \\
\text { prevention, } \mathrm{n}(\%)\end{array}$ & $44(2.9)$ & $45(2.5)$ & $50(2.8)$ & $49(2.8)$ & $61(3.9)$ & $46(2.9)$ & $76(4.5)$ & $75(5.2)$ & 278 (15.5) & $550(27.0)$ & $751(29.7)$ & $583(24.6)$ & $381(17.4)$ & $435(18.9)$ & $412(17.5)$ & \\
\hline \multirow{2}{*}{\multicolumn{17}{|c|}{ Aetiology of the most $p$}} \\
\hline & & & & & & & & & & & & & & & & \\
\hline ACS, $n(\%)$ & $571(370)$ & 633 & 4) & 88.2) & 66.7) & $(68.1)$ & 55.5) & .7) & & & 3.6) & 7.9) & 38.8) & 42.8) & 11.6) & 0.0 \\
\hline CHF, n (\%) & $41(2.7)$ & $30(1.7)$ & $30(1.7)$ & $30(1.7)$ & $32(2.4)$ & $27(1.7)$ & $27(1.8)$ & $43(1.6)$ & 4 & $35(1.7)$ & $45(1.8)$ & $38(1.6)$ & $62(2.8)$ & $44(1.9)$ & $49(2.1)$ & \\
\hline CABG, $n(\%$ & & & & & & & & & & & & & & & $44(1.9)$ & \\
\hline $\mathrm{PCl}, \mathrm{n}(\%)$ & $79(5.1)$ & $150(8.5)$ & 9) & (3.5) & 0.3) & .2) & 5 & .8) & $r$ & 0 & .4) & 2) & $4(0.6)$ & (0.3) & $10(0.4)$ & \\
\hline Other, $\mathrm{n}(\%$ & & & & & & & & & & & & & & 6) & & \\
\hline $\begin{array}{l}\text { No prior hospitalisation/referred } \\
\text { as outpatient, } n(\%)\end{array}$ & $178(11.5)$ & $179(10.1)$ & $176(9.7)$ & $181(10.4)$ & 167 (10.5) & $186(11.7)$ & 203 (12.0) & $161(11.2)$ & $26(18.1)$ & $33(27.1)$ & $04(27.8)$ & $06(25.5)$ & 80 (21.9) & 510 (22.2) & 525 (22.3) & \\
\hline \multicolumn{17}{|l|}{$\begin{array}{l}\text { as outpatient, } \mathrm{n}(\%) \\
\text { Cardiovascular risk factors }\end{array}$} \\
\hline Diabete & & & & & & & & & & & & & & & & \\
\hline Hypert & 5 & 6 & 1) & & & & & & & 3.3) & 8.5) & $9.3)$ & $2.6)$ & 2.3) & (44.1) & $<0.0$ \\
\hline Smokin & $95(7.6)$ & 106 & & 75 & 65 & & & & & & & & $64(4.8)$ & $64(3.6)$ & $37(2.2)$ & $<0.0$ \\
\hline Mean tc & & & & & & & & & & & & & 04 & $4.0 \pm 0.04$ & $4.0 \pm 0.04$ & $<0 . c$ \\
\hline Mean LI & $3.1 \pm 0.07$ & $3.1 \pm 0$ & 3 & & & & & & & & & & & & $2.2 \pm 0.03$ & $<0.0$ \\
\hline Mean $\mathrm{HL}$ & $1.0 \pm 0.02$ & 1. & $1.1 \pm 0.02$ & & & & & & & & .01 & 0.01 & $=0.01$ & $1.2 \pm 0.02$ & $1.2 \pm 0.01$ & 0.0 \\
\hline Mean BMI, kg/m & $28.2 \pm 0.13$ & $28.0 \pm 0.12$ & $28.3 \pm 0.13$ & $28.2 \pm 0.13$ & $28.3 \pm 0.14$ & $28.5 \pm 0.14$ & 28.6 & $28.6 \pm 0.15$ & $28.7 \pm 0.15$ & \pm 0.18 & $29.7 \pm 0.16$ & $29.3 \pm 0.15$ & $29.3 \pm 0.18$ & $29.1 \pm 0.16$ & $29.0 \pm 0.15$ & $<0.0$ \\
\hline Mean a & $96.5 \pm 0.36$ & $96.5 \pm 0.35$ & 0.34 & 0.35 & & & & 97 & 0.40 & & 9 & \pm 5.71 & $106.5 \pm 5.92$ & 0.64 & $99.3 \pm 0.61$ & \\
\hline Mean hip girth, mm & $103.5 \pm 0.30$ & $103.2 \pm .025$ & $103.8 \pm 0.27$ & $103.3 \pm .031$ & $103.2 \pm 0.30$ & $103.0 \pm 0.37$ & $103.5 \pm 0.74$ & $103.2 \pm 0.33$ & $103.8 \pm 0.37$ & $104.4 \pm 0.42$ & $106.3 \pm 0.34$ & $112.0 \pm 5.67$ & $111.7 \pm 5.94$ & $105.9 \pm 0.79$ & $103.7 \pm 0.40$ & 0.0 \\
\hline $\begin{array}{l}\text { Mean baseline peak oxygen } \\
\text { uptake, } \mathrm{m} / \mathrm{kg} / \mathrm{min}\end{array}$ & $18.0 \pm 0.15$ & $19.1 \pm 0.15$ & $25+14$ & 0 & $18.5 \pm 0.15$ & $17.6 \pm 0.15$ & & $16.4 \pm 0.16$ & 014 & $17.7 \pm 0.13$ & $17.9 \pm 0.12$ & $17.9 \pm 0.13$ & $19.3 \pm 0.14$ & $20.0 \pm 0.16$ & $19.6 \pm 0.17$ & \\
\hline
\end{tabular}
uptake, $\mathrm{ml} / \mathrm{kg} / \mathrm{min}$

*p Value examines group differences over time; categorical variables incorporate the Mantel-Haenszel $\chi^{2}$ test for trend; continuous variables examine group differences in means over time using $t$ test. For continuous variables, $p$ values for group differences over time are similar with or without accounting for individual-level variations unless otherwise specified below.

$\dagger$ Ascertained from CR records among those with available data. All other data elements ascertained from administrative data.

$\ddagger$ When accounting for individual variations in $\mathrm{HDL}$ cholesterol, $p$ value in $\mathrm{HDL}$ cholesterol over time, $p<0.001$.

$\S$ When accounting for individual variations in abdominal girth, $p$ value in abdominal girth over time, $p<0.001$.

TWhen accounting for individual variations in hip girth over time, $p$ value in hip girth over time, $p=0.01$.

**When accounting for individual variations in peak oxygen uptake over time, $p$ value in peak oxygen uptake over time, $p<0.001$

ACS, acute coronary syndromes; BMI, body mass index; CABG, coronary artery bypass graft; CR, cardiac rehabilitation; CVD, cardiovascular disease; HDL, high-density lipoprotein;

LDL, low-density lipoprotein; $\mathrm{PCl}$, percutaneous coronary intervention. 

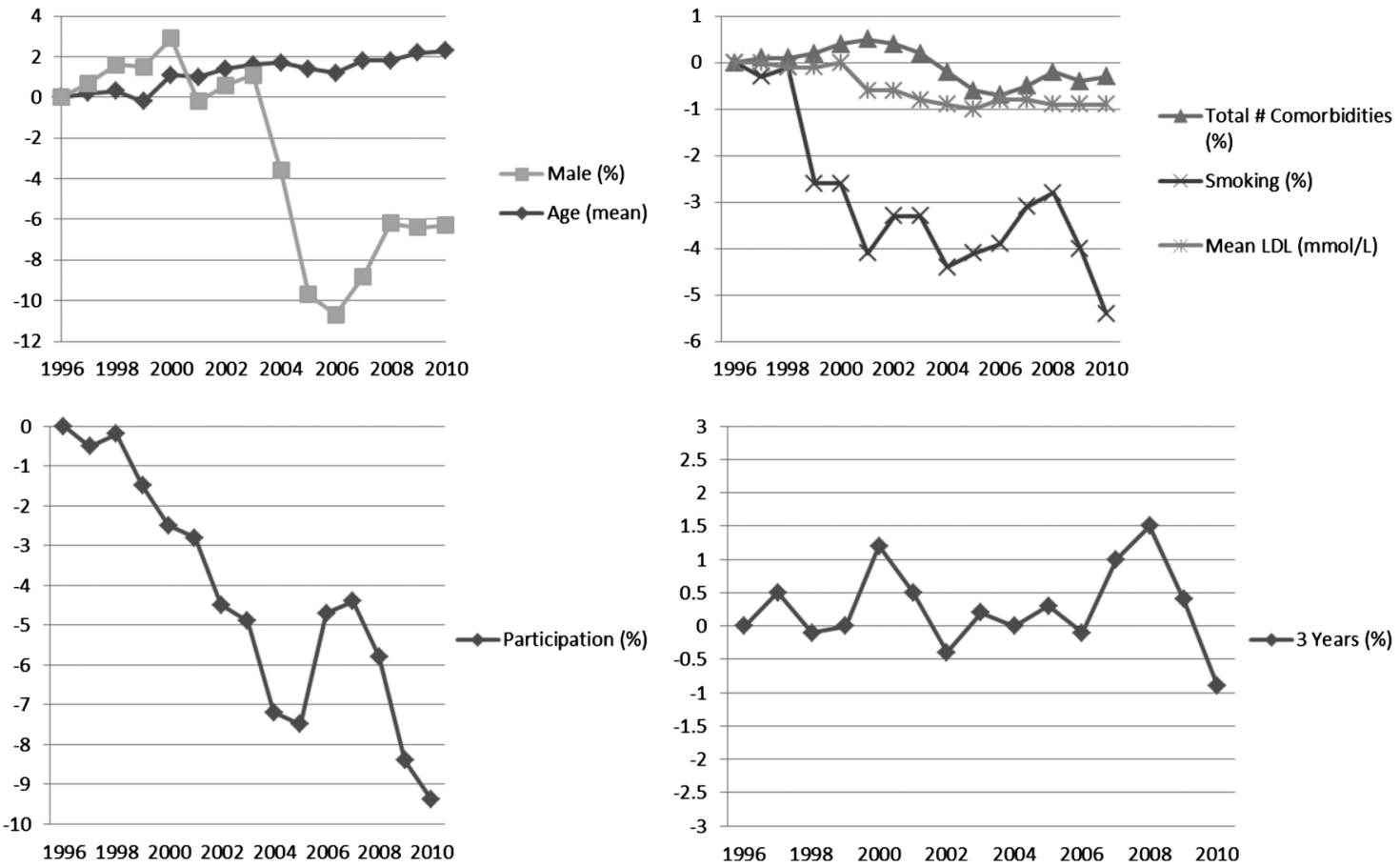

Figure 1 Temporal changes, relative to 1996. Temporal changes in (A) sociodemographic characteristics (sex $p<0.001$ and age $p<0.001$ for change over time); (B) clinical characteristics (comorbidities $p<0.001$, smoking $p<0.001$ and low-density lipoprotein $(\mathrm{LDL}) \mathrm{p}<0.001$ ); (C) cardiac rehabilitation participation (\% of prescribed sessions attended among patients who at least attended one session postintake assessment; $p<0.001)$; and $(D)$ mortality $(p=0.97)$.

mixed picture of referral patterns emerged over time, suggesting complex, implicit referral selection processes, or even patient 'cherry picking' (ie, selection of highfunctioning patients) by referring physicians, may be at play. ${ }^{21}$ While more sociodemographically diverse patients were referred, CR adherence was lower. The beneficial outcomes associated with CR participation cannot be realised in the real world with such low adherence. In accordance with these participation rates, there was a neutral effect in terms of 1-year, 2-year and 3-year mortality over time. Moreover, mortality was low, which speaks to the highly selected nature of the referred population.

The overall number of patients referred increased from 2005 onward. This trend is consistent with the referral patterns observed throughout the remainder of the province from 2000 to $2007 .^{22}$ There could be several explanations for this. More percutaneous coronary intervention, high-risk primary prevention as well as patients with other non-ischaemic cardiac indications were being referred, and also many more outpatients were referred. With regard to the former, the volume of percutaneous coronary interventions has increased drastically. ${ }^{23}$ The increase could also reflect greater awareness in the cardiology community of the benefits of CR, and wider adherence to guideline recommendations for CR referral, ${ }^{9}$ particularly given the CR programme leadership actively formed connections with referral partners throughout the period of study. Increases in referral rates have been observed in registries in other jurisdictions as well. ${ }^{13}$ However, the eligible population or denominator of patients is unknown, and therefore interpretation of these findings should be made cautiously.

The sociodemographic characteristics of referred patients trended towards greater heterogeneity over time. Historically, younger, married males have been disproportionately represented in $\mathrm{CR},{ }^{24-26}$ so it is encouraging to see more diversity in the characteristics of patients referred. This is again consistent with other jurisdictions. ${ }^{13}{ }^{14}$ Specifically, several of the observations herein are consistent with temporal trends observed in the USA. ${ }^{20}$ Audelin et al observed increasing age, as well as increases in risk factors-namely diabetes, obesity and hypertension. These risk factors trends have similarly been reported in Canada. ${ }^{2}{ }^{27}$ They also observed the trends towards lower cholesterol, and concluded this likely reflects greater prescription of statins at higher doses in cardiology and general practice. Contrarily, Audelin et al did not observe an increase in female referrals; however, they only observed trends through 2006. Moreover, they observed a trend towards lower functional capacity at intake, whereas no change was observed herein.

The higher referral volumes may have resulted in longer wait times to initiate CR, which have been shown to be related to lower enrolment rates. ${ }^{28}$ This could also contribute to the lower programme adherence observed over time. The declining participation rates may also suggest that CR programmes in Canada are not adapting services to optimally engage more socioeconomically 
Table 2 Temporal trends in comorbidities of cardiac rehabilitation patients between 1996 and 2010

\begin{tabular}{|c|c|c|c|c|c|c|c|c|c|c|c|c|c|c|c|c|}
\hline \multirow{2}{*}{$\begin{array}{l}\text { Baseline } \\
\text { characteristics }\end{array}$} & \multicolumn{15}{|l|}{ Year } & \multirow[b]{2}{*}{ p Value* } \\
\hline & 1996 & 1997 & 1998 & 1999 & 2000 & 2001 & 2002 & 2003 & 2004 & 2005 & 2006 & 2007 & 2008 & 2009 & 2010 & \\
\hline $\mathrm{N}$ & 1545 & 1773 & 1818 & 1736 & 1586 & 1596 & 1686 & 1444 & 1799 & 2041 & 2532 & 2374 & 2188 & 2298 & 2351 & \\
\hline \multicolumn{17}{|c|}{ Comorbidities, N (\%) } \\
\hline Mean number & \pm 0.06 & $3.8 \pm 0.06$ & $3.8 \pm 0.06$ & $3.9 \pm 0.06$ & $4.1 \pm 0.07$ & $4.2 \pm 0.07$ & $4.1 \pm 0.07$ & $3.9 \pm 0.07$ & $3.5 \pm 0.07$ & $3.1 \pm 0.07$ & $3.0 \pm 0.06$ & $3.2 \pm 0.06$ & $3.5 \pm 0.07$ & $3.3 \pm 0.06$ & $3.4 \pm 0.06$ & $<0.001$ \\
\hline$<2, \mathrm{n}(\%)$ & $\begin{array}{l}303 \\
(19.6)\end{array}$ & $\begin{array}{l}324 \\
(18.3)\end{array}$ & 331 (18.2) & $\begin{array}{l}295 \\
(17.0)\end{array}$ & $\begin{array}{l}269 \\
(17.0)\end{array}$ & $\begin{array}{l}274 \\
(17.2)\end{array}$ & $\begin{array}{l}313 \\
(18.6)\end{array}$ & $\begin{array}{l}271 \\
(18.8)\end{array}$ & $483(26.9)$ & $716(35.1)$ & $928(36.7)$ & $812(34.2)$ & $647(29.6)$ & 709 (30.9) & $729(31.0)$ & $<0.001$ \\
\hline $2-4.9, n(\%)$ & $\begin{array}{l}707 \\
(45.8)\end{array}$ & $\begin{array}{l}815 \\
(46.0)\end{array}$ & $881(48.5)$ & $\begin{array}{l}802 \\
(46.2)\end{array}$ & $\begin{array}{l}684 \\
(43.1)\end{array}$ & $\begin{array}{l}665 \\
(41.7)\end{array}$ & $\begin{array}{l}710 \\
(42.1)\end{array}$ & $\begin{array}{l}652 \\
(45.2)\end{array}$ & $8(41.0)$ & $775(38.0)$ & $903(35.7)$ & $869(36.6)$ & $820(37.5)$ & $910(39.6)$ & $898(38.2)$ & \\
\hline $5+, \mathrm{n}(\%)$ & $\begin{array}{l}535 \\
(34.6)\end{array}$ & $\begin{array}{l}634 \\
(35.8)\end{array}$ & $606(33.3)$ & $\begin{array}{l}639 \\
(36.8)\end{array}$ & $\begin{array}{l}633 \\
(39.9)\end{array}$ & $\begin{array}{l}657 \\
(41.2)\end{array}$ & $\begin{array}{l}663 \\
(39.3)\end{array}$ & $\begin{array}{l}521 \\
(36.1)\end{array}$ & $578(32.1)$ & $550(27.0)$ & $701(27.7)$ & $693(29.2)$ & $721(33.0)$ & $679(29.6)$ & $724(30.8)$ & \\
\hline \multicolumn{17}{|c|}{ Cardiac comorbidities, $n(\%)$} \\
\hline Mean number & $1.7 \pm 0.04$ & $1.8 \pm 0.04$ & $1.9 \pm 0.04$ & $2.2 \pm 0.04$ & $2.4 \pm 0.05$ & $2.5 \pm 0.05$ & $2.4 \pm 0.05$ & $2.4 \pm 0.05$ & $2.1 \pm 0.05$ & $1.9 \pm 0.04$ & $1.8 \pm 0.04$ & $1.9 \pm 0.04$ & $2.0 \pm 0.04$ & $1.9 \pm 0.04$ & $2.0 \pm 0.04$ & 0.002 \\
\hline$<2, \mathrm{n}(\%)$ & $\begin{array}{l}303 \\
(29.0)\end{array}$ & $\begin{array}{l}324 \\
(27.5)\end{array}$ & $331(26.2)$ & $\begin{array}{l}295 \\
(24.4)\end{array}$ & $\begin{array}{l}269 \\
(24.7)\end{array}$ & $\begin{array}{l}274 \\
(24.6)\end{array}$ & $\begin{array}{l}313 \\
(26.8)\end{array}$ & $\begin{array}{l}271 \\
(26.1)\end{array}$ & $483(35.5)$ & $716(44.0)$ & $928(46.1)$ & $812(43.9)$ & $647(39.0)$ & $709(39.2)$ & $729(40.1)$ & $<0.001$ \\
\hline $2-4.9, n(\%)$ & $\begin{array}{l}707 \\
(67.7)\end{array}$ & $\begin{array}{l}815 \\
(69.1)\end{array}$ & $881(69.8)$ & $\begin{array}{l}802 \\
(66.4)\end{array}$ & $\begin{array}{l}684 \\
(62.9)\end{array}$ & $\begin{array}{l}665 \\
(59.8)\end{array}$ & $\begin{array}{l}710 \\
(60.7)\end{array}$ & $\begin{array}{l}652 \\
(62.8)\end{array}$ & $738(54.3)$ & $738(47.6)$ & $903(44.8)$ & $869(47.0)$ & $820(49.4)$ & $910(50.3)$ & $898(49.4)$ & \\
\hline $5+, \mathrm{n}(\%)$ & $35(3.4)$ & $40(3.4)$ & $51(4.0)$ & $111(9.2)$ & $\begin{array}{l}135 \\
(12.4)\end{array}$ & $\begin{array}{l}174 \\
(15.6)\end{array}$ & $\begin{array}{l}147 \\
(12.6)\end{array}$ & $\begin{array}{l}116 \\
(11.2)\end{array}$ & $139(10.2)$ & $138(8.5)$ & $183(9.1)$ & $168(9.1)$ & $194(11.7)$ & $191(10.6)$ & $192(10.7)$ & \\
\hline \multicolumn{17}{|l|}{ Non-cardiac comor } \\
\hline Mean number & $2.2 \pm 0.03$ & $2.3 \pm 0.03$ & $2.2 \pm 0.03$ & $2.0 \pm 0.04$ & $2.0 \pm 0.04$ & $2.1 \pm 0.04$ & $2.0 \pm 0.04$ & $1.8 \pm 0.04$ & $1.7 \pm 0.04$ & $1.6 \pm 0.04$ & $1.5 \pm 0.03$ & $1.6 \pm 0.03$ & $1.8 \pm 0.04$ & $1.7 \pm 0.04$ & $1.7 \pm 0.04$ & $<0.001$ \\
\hline$<2, \mathrm{n}(\%)$ & $\begin{array}{l}554 \\
(35.9)\end{array}$ & $622(35.1$ & $648(35.6)$ & $\begin{array}{l}771 \\
(44.4)\end{array}$ & $\begin{array}{l}725 \\
(45.7)\end{array}$ & $\begin{array}{l}738 \\
(46.2)\end{array}$ & $\begin{array}{l}847 \\
(50.2)\end{array}$ & $\begin{array}{l}766 \\
(53.1)\end{array}$ & $\begin{array}{l}1058 \\
(58.8)\end{array}$ & $\begin{array}{l}1228 \\
(60.2)\end{array}$ & $\begin{array}{l}1591 \\
(62.8)\end{array}$ & $\begin{array}{l}1423 \\
(59.9)\end{array}$ & $\begin{array}{l}1241 \\
(56.7)\end{array}$ & $\begin{array}{l}1372 \\
(59.7)\end{array}$ & $\begin{array}{l}1366 \\
(58.1)\end{array}$ & $<0.001$ \\
\hline $2-4.9, \mathrm{n}(\%)$ & $\begin{array}{l}867 \\
(56.1)\end{array}$ & $\begin{array}{l}981 \\
(55.3)\end{array}$ & $\begin{array}{l}1021 \\
(56.2)\end{array}$ & $\begin{array}{l}794 \\
(45.7)\end{array}$ & $\begin{array}{l}696 \\
(43.9)\end{array}$ & $\begin{array}{l}691 \\
(43.3)\end{array}$ & $\begin{array}{l}654 \\
(38.8)\end{array}$ & $\begin{array}{l}552 \\
(38.2)\end{array}$ & $566(31.5)$ & $654(32.0)$ & $751(29.7)$ & $753(31.7)$ & 704 (32.2) & $712(31.0)$ & $763(32.5)$ & \\
\hline $5+, \mathrm{n}(\%)$ & $124(8.0)$ & $170(9.6)$ & 149 (8.2) & 171 (9.9) & $\begin{array}{l}165 \\
(10.4)\end{array}$ & $\begin{array}{l}167 \\
(10.5)\end{array}$ & $\begin{array}{l}185 \\
(11.0)\end{array}$ & $126(8.7)$ & $175(9.7)$ & $159(7.8)$ & $190(7.5)$ & 198 (8.3) & $243(11.1)$ & 214 (9.3) & $22(9.4)$ & \\
\hline
\end{tabular}

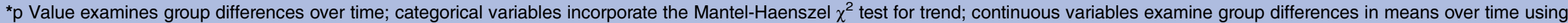
$t$ Test. For continuous variables, $p$ values for group difference over time are similar with or without accounting for individual-level variations. 


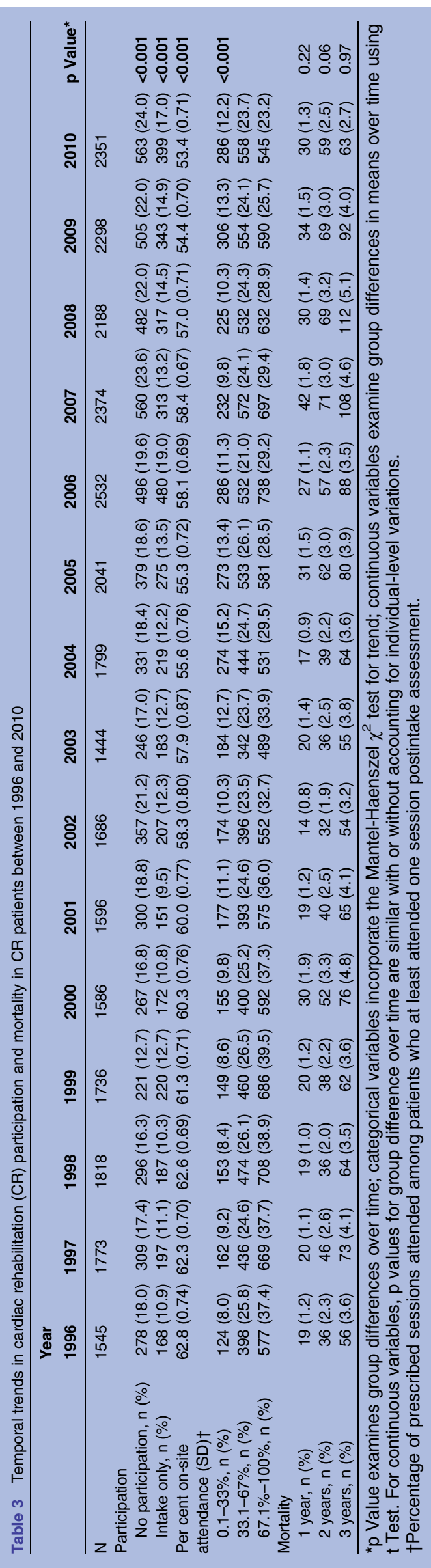

diverse and older populations. Such observations may be unique to Canada. For instance, despite similar sociodemographic referral trends in the USA, evidence suggests that CR participation remained unchanged. ${ }^{14}$ These differences may be explained by the different payment models that exist in the USA (ie, healthcare insurance) and Canada (ie, public universal healthcare), such that patients in the former are only referred if they have coverage, and patients with coverage may be more likely to participate. Unfortunately, there are no clear evidence-based interventions which robustly increase programme adherence, ${ }_{30}^{29}$ particularly in these historically underserved groups. ${ }^{30}$

The neutral trend in mortality could be related to the confluence of lower rates of programme participation, the nature of participating patients being older and of lower socioeconomic status, improvements in secondary preventive care over time, and variation in risk factor control with some increasing and some decreasing. Patients with CVD are also surviving longer, and subsequently are living longer with more comorbidities. ${ }^{31}$ It was curious that the proportion of patients with noncardiac comorbidities was observed to be declining over time. Patients with more comorbidities may be less inclined to participate. However, a study in all tertiary cardiac centres in the province of Ontario showed that patients with comorbid pulmonary, renal or peripheral vascular disease were significantly less likely to be referred. ${ }^{32}$ These more complex patients in particular warrant referral to $\mathrm{CR}$, where the repeated contacts with healthcare providers could ensure fulsome clinical management and greater opportunity for patient education regarding control of multimorbidity. Indeed, research has established the multifactorial benefits of CR participation in patients with comorbidities. ${ }^{33}$

Caution is warranted in interpreting these findings. First, the design was observational, and therefore some alternative explanations for the associations observed cannot be ruled out. Second, this was a single-centre study, and hence generalisability to other centres is unknown. Third, extensive validation studies of the case ascertainment of disease-specific comorbidities have been undertaken in Ontario. These have demonstrated high specificities, but variable sensitivities. ${ }^{34} 35$ Fourth, findings regarding changes in referral indications should be interpreted with caution due to the approach taken to categorisation herein. Fifth, it is possible that a patient may have been referred twice or more at separate points throughout the 14 years of follow-up, leading to some potential duplication. This however would likely be minor, and not have an appreciable effect on the findings observed. Sixth, while we had $100 \%$ availability of administrative data in the linked cohort including mortality, there was some missingness of clinical data from the CR site. Finally, results may not be generalisable to jurisdictions with CR payment models different than single payer. 


\section{CONCLUSIONS}

In conclusion, physicians appear to be referring more sociodemographically diverse patients to CR. These patients however appear less likely to enrol and participate in prescribed sessions. Programmes may need to adapt to better engage these older, single, female patients of lower socioeconomic status. Patients who have non-cardiac comorbidities were less likely to be referred over time, despite greater need. Mortality remained stable at 5\%. Findings suggest the need for explicit, criteria-based referral processes for $\mathrm{CR}$ and implementation of evidence-based strategies to promote CR participation.

Contributors SLG contributed to the conception of the work, the acquisition, analysis and interpretation of data, drafting and revising manuscript, and final approval of the version published. PIO, SM, TC and YT contributed to the design of the work, revising manuscript and final approval of the version published. DAA contributed to the conception of the work, drafting and revising manuscript, the acquisition, analysis and interpretation of data, and final approval of the version published. All authors agree be accountable for all aspects of the work in ensuring that questions related to the accuracy or integrity of any part of the work are appropriately investigated and resolved.

Funding This study was funded by Investigator-Initiated funds. The Institute for Clinical Evaluative Sciences (ICES) is funded by an annual grant from the Ontario Ministry of Health and Long-Term Care (MOHLTC). The opinions, results and conclusions reported in this paper are those of the authors and are independent from the funding sources. DAA is a Career Investigator with the Heart and Stroke Foundation of Ontario and Research Chair in Cardiovascular and Metabolic Rehabilitation, Toronto Rehabilitation Institute-University Health Network, University of Toronto.

Competing interests None declared.

Ethics approval University Health Network.

Provenance and peer review Not commissioned; externally peer reviewed.

Data sharing statement No additional data are available.

Open Access This is an Open Access article distributed in accordance with the Creative Commons Attribution Non Commercial (CC BY-NC 4.0) license, which permits others to distribute, remix, adapt, build upon this work noncommercially, and license their derivative works on different terms, provided the original work is properly cited and the use is non-commercial. See: http:// creativecommons.org/licenses/by-nc/4.0/

\section{REFERENCES}

1. Tu JV, Nardi L, Fang J, et al. National trends in rates of death and hospital admissions related to acute myocardial infarction, heart failure and stroke, 1994-2004. CMAJ 2009;180:E118-25.

2. Lee DS, Chiu M, Manuel DG, et al. Trends in risk factors for cardiovascular disease in Canada: temporal, socio-demographic and geographic factors. CMAJ 2009;181:E55-66.

3. Heran BS, Chen JM, Ebrahim S, et al. Exercise-based cardiac rehabilitation for coronary heart disease. Cochrane database Syst Rev 2011;(7):CD001800.

4. Chan PS, Oetgen WJ, Buchanan D, et al. Cardiac performance measure compliance in outpatients: the American College of Cardiology and National Cardiovascular Data Registry's PINNACLE (Practice Innovation And Clinical Excellence) program. J Am Coll Cardiol 2010;56:8-14.

5. Turk-Adawi K, Sarrafzadegan N, Grace SL. Global availability of cardiac rehabilitation. Nat Rev Cardiol 2014;11:586-96.

6. Candido E, Richards JA, Oh P, et al. The relationship between need and capacity for multidisciplinary cardiovascular risk-reduction programs in Ontario. Can J Cardiol 2011;27:200-7.

7. Arena R, Williams M, Forman DE, et al. Increasing referral and participation rates to outpatient cardiac rehabilitation: the valuable role of healthcare professionals in the inpatient and home health settings: a science advisory from the American Heart Association. Circulation 2012;125:1321-9.

8. Balady GJ, Fletcher BJ, Froelicher ES, et al. Cardiac rehabilitation programs. A statement for healthcare professionals from the American Heart Association. Circulation 1994:90:1602-10.

9. Grace SL, Chessex $\mathrm{C}$, Arthur $\mathrm{H}$, et al. Systematizing inpatient referral to cardiac rehabilitation 2010: Canadian Association of Cardiac Rehabilitation and Canadian Cardiovascular Society joint position paper endorsed by the Cardiac Care Network of Ontario. Can J Cardiol 2011;27:192-9.

10. Gravely-Witte S, Leung YW, Nariani R, et al. Effects of cardiac rehabilitation referral strategies on referral and enrollment rates. Nat Rev Cardiol 2010;7:87-96.

11. Grace SL, Russell KL, Reid RD, et al. Effect of cardiac rehabilitation referral strategies on utilization rates: a prospective, controlled study. Arch Intern Med 2011;171:235-41.

12. Grace SL, Leung YW, Reid R, et al. The role of systematic inpatient cardiac rehabilitation referral in increasing equitable access and utilization. J Cardiopulm Rehabil Prev 2012;32:41-7.

13. Beatty AL, Li S, Thomas L, et al. Trends in referral to cardiac rehabilitation after myocardial infarction: data from the National Cardiovascular Data Registry 2007 to 2012. J Am Coll Cardiol 2014:63:2582-3.

14. Dunlay SM, Pack QR, Thomas RJ, et al. Participation in cardiac rehabilitation, readmissions, and death after acute myocardial infarction. Am J Med 2014;127:538-46.

15. Taylor GH, Wilson SL, Sharp J. Medical, psychological, and sociodemographic factors associated with adherence to cardiac rehabilitation programs: a systematic review. J Cardiovasc Nurs 2011;26:202-9.

16. Samayoa L, Grace SL, Gravely S, et al. Sex differences in cardiac rehabilitation enrollment: a meta-analysis. Can J Cardiol 2014;30:793-800

17. Martin BJ, Hauer T, Arena R, et al. Cardiac rehabilitation attendance and outcomes in coronary artery disease patients. Circulation 2012;126:677-87.

18. Stone JA, Suskin N, Arthur HM. In: Stone JA, ed. Canadian guidelines for cardiac rehabilitation and cardiovascular disease prevention: translating knowledge into action. 3rd edn. Winnipeg, MB, Canada: Canadian Association of Cardiac Rehabilitation, 2009.

19. Marzolini S, Brooks D, Oh PI. Sex differences in completion of a 12-month cardiac rehabilitation programme: an analysis of 5922 women and men. Eur J Cardiovasc Prev Rehabil 2008;15:698-703.

20. Audelin MC, Savage PD, Ades PA. Changing clinical profile of patients entering cardiac rehabilitation/secondary prevention programs: 1996 to 2006. J Cardiopulm Rehabil Prev 2008;28:299-306.

21. Beckstead JW, Pezzo MV, Beckie TM, et al. Physicians' tacit and stated policies for determining patient benefit and referral to cardiac rehabilitation. Med Decis Making 2014;34:63-74.

22. Nguyen TN, Abramson BL, Galluzzi A, et al. Temporal trends and referral factors for cardiac rehabilitation post-acute coronary syndrome in Ontario: insights from the Canadian Global Registry of Acute Coronary Events. Can J Cardiol 2013;29:1604-9.

23. Faris PD, Grant FC, Galbraith PD, et al. Diagnostic cardiac catheterization and revascularization rates for coronary heart disease. Can J Cardiol 2004;20:391-7.

24. Jackson L, Leclerc J, Erskine Y, et al. Getting the most out of cardiac rehabilitation: a review of referral and adherence predictors. Heart 2005;91:10-14.

25. Valencia HE, Savage PD, Ades PA. Cardiac rehabilitation participation in underserved populations. Minorities, low socioeconomic, and rural residents. J Cardiopulm Rehabil Prev 2011;31:203-10.

26. Colella TJ, Gravely S, Marzolini S, et al. Sex bias in referral of women to outpatient cardiac rehabilitation? A meta-analysis. Eur $J$ Prev Cardiol 2015;22:423-41.

27. Maclagan LC, Park J, Sanmartin C, et al. The CANHEART health index: a tool for monitoring the cardiovascular health of the Canadian population. CMAJ 2014;186:180-7.

28. Russell KL, Holloway TM, Brum M, et al. Cardiac rehabilitation wait times: effect on enrollment. $J$ Cardiopulm Rehabil Prev 2011;31:373-7.

29. Karmali KN, Davies P, Taylor F, et al. Promoting patient uptake and adherence in cardiac rehabilitation. Cochrane Database Syst Rev 2014;(6):CD007131.

30. Beswick AD, Rees K, Griebsch I, et al. Provision, uptake and cost of cardiac rehabilitation programmes: improving services to underrepresented groups. Health Technol Assess 2004;8:iii-iv, ix-x, 1-152.

31. Ford ES, Ajani UA, Croft JB, et al. Explaining the decrease in U.S. deaths from coronary disease, 1980-2000. N Engl J Med 2007;356:2388-98. 
32. Brady S, Purdham D, Oh P, et al. Clinical and sociodemographic correlates of referral for cardiac rehabilitation following cardiac revascularization in Ontario. Heart Lung 2013; 42:320-5

33. Listerman J, Bittner V, Sanderson BK, et al. Cardiac rehabilitation outcomes: impact of comorbidities and age. J Cardiopulm Rehabil Prev 2011;31:342-8.
34. Hux JE, Ivis F, Flintoft V, et al. Diabetes in Ontario: determination of prevalence and incidence using a validated administrative data algorithm. Diabetes Care 2002;25:512-16.

35. Austin PC, Stanbrook MB, Anderson GM, et al. Comparative ability of comorbidity classification methods for administrative data to predict outcomes in patients with chronic obstructive pulmonary disease. Ann Epidemiol 2012;22:881-7. 